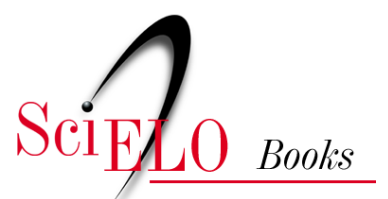

\title{
Capítulo 3. Demografia, epidemias e organização social os Xavánte de Pimentel Barbosa (Etéñitépa), Mato Grosso
}

\author{
Ricardo Ventura Santos \\ Nancy M. Flowers \\ Carlos E. A. Coimbra Jr.
}

\section{SciELO Books / SciELO Livros / SciELO Libros}

SANTOS, R.V., FLOWERS, N.M., and COIMBRA JR., C.E.A. Demografia, epidemias e organização social: os Xavánte de Pimentel Barbosa (Etéñitépa), Mato Grosso. In: PAGLIARO, H., AZEVEDO, MM., and SANTOS, RV., comps. Demografia dos povos indígenas no Brasil [online]. Rio de Janeiro: Editora FIOCRUZ, 2005, pp. 59-78. Saúde dos Povos Índigenas collection. ISBN: 978-85-7541-254-1. https://doi.org/10.7476/9788575412541.0004.

\section{(9)(@)}

All the contents of this work, except where otherwise noted, is licensed under a Creative Commons Attribution-Non Commercial-ShareAlike 3.0 Unported.

Todo o conteúdo deste trabalho, exceto quando houver ressalva, é publicado sob a licença Creative Commons Atribuição - Uso Não Comercial - Partilha nos Mesmos Termos 3.0 Não adaptada. 


\section{Demografia, Epidemias e Organização Social: os Xavánte de Pimentel Barbosa (Etéñitépa), Mato Grosso ${ }^{1}$}

\section{Introdução}

No livro Os Índios e a Civilização, Darcy Ribeiro (1977) escreveu um longo capítulo sobre as epidemias e suas conseqüências sobre os povos indígenas. Nele, cujo título é 'Convívio e contaminação', o antropólogo afirma que "bacilos e vírus" foram importantes "armas de conquista", tendo contribuído sobremaneira para o processo de subjugação das sociedades indígenas em face do expansionismo ocidental. Inovador para sua época (o texto foi originalmente escrito na década de 1950), a descrição de Ribeiro sobre "os efeitos dissociativos da depopulação e do debilitamento por eles provocados" (1977:273) beira o senso comum nos dias atuais, algo amplamente conhecido em virtude de sua recorrência histórica.

Sabemos que, em seus determinantes e conseqüências, o quadro esboçado por Ribeiro não é uma particularidade do Brasil. Muito pelo contrário. Se, por um lado, os povos indígenas das Américas, do Ártico ao extremo sul da América do Sul (somente no Brasil são atualmente em torno de 220 povos, falantes de cerca de 180 línguas diferentes), apresentam grande diversidade histórica, social e cultural, por outro, compartilham de uma devastadora experiência: a ocorrência de severas crises demográficas, que resultaram em acentuadas reduções populacionais e extinção de inúmeras sociedades a partir da chegada dos colonizadores. Embora antropólogos, demógrafos e historiadores estejam longe de um consenso acerca da intensidade da depopulação ocorrida desde o século XV (alguns chegam a afirmar que foi da ordem de $80 \%$ ou mais), não há dúvidas de que as principais causas da elevada mortalidade foram epidemias de doenças infecciosas e parasitárias (Crosby, 1972; Dobyns, 1983; Hemming, 1987; Gomes, 1988; Denevan, 1992; Cook, 1998).

Apesar de sua recorrência e da potencial ameaça à sobrevivência biológica e cultural dos povos indígenas, as dinâmicas dessas crises demográficas são pouco conhecidas. Um aspecto especialmente importante é compreender como as estruturas sociais das sociedades indígenas podem ter sido afetadas pelas epidemias e pela conseqüente depopulação. Esse ponto recebeu atenção de alguns 
antropólogos, como o próprio Ribeiro, que apresenta em seu livro uma série de exemplos das "profundas mudanças na distribuição e nas inter-relações dos vários grupos locais, no sistema associativo, na forma de família, de casamento, de todas as instituições tribais". Algo bem menos explorado na literatura etnológica é a recíproca, qual seja, como as características sociais de uma dada sociedade podem influenciar o curso da crise e a eventual recuperação demográfica subseqüente. A parca literatura acerca do modo como a estrutura social das sociedades indígenas pode ter sido afetada pelas epidemias e pela conseqüente depopulação (e viceversa) é particularmente surpreendente diante da longa tradição de pesquisas em etnologia indígena no Brasil.

O estudo de caso sobre os Xavánte que se aborda neste trabalho tem dois objetivos: primeiro, por meio da análise de dados de fecundidade e de mortalidade, documenta-se a crise demográfica que atingiu o grupo no período pós-contato, a partir da década de 1940; segundo, busca-se argumentar como certos aspectos da organização social Xavánte foram cruciais, afetando não apenas o modo como a crise evoluiu, como também a recuperação demográfica que se seguiu.

\section{Os Xavánte}

Os Xavánte, que no início da década de 1990, quando esta investigação foi realizada, totalizavam cerca de 8 mil indivíduos, vivem em seis Terras Indígenas (T.I.) no leste do estado de Mato Grosso (há uma sétima em processo de desocupação e demarcação, Marãiwasede). A pesquisa foi realizada na T.I. Pimentel Barbosa, onde está localizada a comunidade de Etéñitépa.

No início do século XVIII, quando ocorreram os primeiros contatos com não-índios, os Xavánte localizavam-se no que atualmente é o estado de Goiás, a leste da região que ocupam no presente. Cartas dos governadores coloniais a Lisboa descreviam 'problemas com os índios', demonstrando que os Xavánte e outros grupos resistiam à invasão de suas terras, atacando minas e investindo contra o gado e as plantações dos colonos. O governo da colônia conseguiu 'pacificar' e fixar uma série de grupos, incluindo os Xavánte, em grandes assentamentos de missões. As doenças e a fome reduziram drasticamente seus números. Ao final do século XVIII, a maior parte das missões encontrava-se abandonada. No século e meio segưinte, os Xavánte continuaram a resistir à expansão da colonização, movendose na direção oeste. A autonomia Xavánte foi irreversivelmente quebrada na década de 1940, quando o governo empreendeu esforços para 'desenvolver' as regiões centrais do Brasil.

Em 1946, um subgrupo Xavánte liderado por um chefe chamado Apowe tornou-se o primeiro a estabelecer contato permanente com os agentes do SPI (Serviço de Proteção aos Índios). Membros deste subgrupo e seus descendentes 
vivem atualmente na T.I. Pimentel Barbosa. No início dos anos 90, encontravamse assentados em uma aldeia principal, denominada Etéñitépa, e em duas menores (Caçula e Tanguro).

Durante os dez primeiros anos após o contato permanente (1946-1956), os Xavánte de Etéñitépa permaneceram relativamente isolados e independentes. Continuavam a praticar uma estratégia de subsistência baseada na caça e na coleta, com a agricultura ocupando um plano secundário. Durante os quinze anos seguintes, de 1957 a 1971, sofreram os devastadores efeitos do contato, com muitas epidemias e mudanças nas estratégias de subsistência. Aumentou então sua dependência da agricultura. As décadas de 1970 e 1980 foram períodos de recuperação demográfica. Foi também um tempo de intensos esforços para garantirem seus direitos às terras. No final da década de 70 e início da de 80, os Xavánte participaram de um projeto governamental de rizicultura mecanizada voltado para o mercado regional. O projeto fracassou e a produção intensiva do arroz foi logo abandonada. Os limites da reserva foram finalmente demarcados e garantidos durante a década de 80 . Como um todo, os dados indicam um período de crise pós-contato durante a década de 60 , seguidos por uma recuperação demográfica. A longo prazo, tem-se observado uma tendência em direção à intensificação das relações com o mercado regional. Para maiores informações acerca da história Xavánte, ver particularmente Coimbra Jr. et al. (2002), Garfield (2001), Graham (1995), Lopes da Silva (1992) e Santos et al. (1997).

\section{Fontes e coleta de dados}

Os dados demográficos analisados neste trabalho derivam de diversos recenseamentos e de histórias reprodutivas de mulheres Xavánte, registrados por Flowers ao longo de 14 meses de pesquisa em Etéñitépa, entre 1976/1977. Na década de 90, quando esta equipe realizou trabalho de campo em Etéñitépa em diversas ocasiões, dados demográficos foram novamente coletados.

Informações disponibilizadas por pesquisadores que trabalharam entre os Xavánte em períodos anteriores foram muito úteis para as análises. As genealogias registradas por Maybury-Lewis (1967:317-342), publicadas em sua monografia Akwe-Shavante Society, forneceram os nomes dos adultos e as relações entre aqueles que viviam na comunidade à época de sua pesquisa, entre 1958 e 1962. O geneticista Jảmes V. Neel gentilmente forneceu-nos cópias de suas anotações de campo, contendo os nomes e as idades estimadas dos indivíduos examinados durante seu trabalho de campo em 1962 (Neel et al., 1964).

Todos aqueles que coletaram dados demográficos em sociedades sem escrita sabem que um dos objetivos mais difíceis de se alcançar, embora essencial, é estabelecer, com a maior precisão possível, as idades dos indivíduos (ver Black et al., 1978; Howell, 1979; Chagnon, 1983; Early G Peters, 1990, 2000; Early G Headland, 
1998; Hill G Hurtado, 1996, entre outros). Em 1977, um dos instrumentos utilizados por Flowers para estimar as idades foi um calendário de eventos, que se mostrou especialmente útil para se perguntar aos pais quanto às datas de nascimento de seus filhos. Exemplos destes eventos são quando os Xavánte tiveram seu primeiro contato pacífico com funcionários do governo (em 1946); quando o antropólogo Maybury-Lewis e sua família viveram entre eles (em 1958); quando o grupo mudouse para a sua atual localização, Etéñitépa (em 1972), e assim por diante. Quando a data de nascimento aproximada podia ser determinada para uma criança, as idades relativas de seus irmãos e irmãs podiam ser estimadas.

A sociedade Xavánte apresenta algumas características que facilitaram nossas investigações demográficas. Diferentemente de outros grupos das terras baixas sul-americanas, como os Suruí (Coimbra Jr., 1989), os Xavánte não possuem proibições quanto a falar a respeito dos mortos. Se isso houvesse ocorrido, recuperar dados demográficos por meio de entrevistas teria sido ainda mais difícil. A estimativa das idades foi ainda facilitada pela existência de um sistema de classes de idade (ver adiante). Os próprios Xavánte usam este sistema, afirmando, por exemplo, que este ou aquele evento ocorreram quando meninos filiados a uma classe de idade determinada ocupavam a casa destinada aos rapazes solteiros (hö).

\section{O ciclo de vida Xavánte}

A organização social dos Xavánte é marcadamente complexa. A relação entre os sistemas de categorias de idade e de classes de idade é exemplar neste sentido. Enquanto as categorias de idade referem-se aos estágios de vida para homens e mulheres (crianças pequenas, adolescentes, jovens adultos e adultos maduros), o sistema de classes de idade é composto por oito classes nomeadas que se alternam em um ciclo de 40-50 anos.

Os meninos entre oito e treze anos de idade tornam-se wapté. Deixam então suas casas e passam a viver em grupo no hö, ou 'casa dos solteiros', especialmente construída para este fim em uma das extremidades da aldeia. $\mathrm{O}$ menino passa a integrar uma classe de idade quando vai residir no hö, onde permanecerá por aproximadamente cinco anos, quando então sua classe será iniciada e poderá casar-se. Os meninos que vivem no hö não são isolados da vida da aldeia. Podem visitar suas casas e trabalhar com seus pais nas roças familiares. O sistema de classes de idade também se aplica às mulheres. Há, contudo, importantes diferenças. As jovens da mesma classe de idade dos wapté não são separadas de suas famílias.

Os sistemas de clãs e de linhagens são duas outras dimensões fundamentais da organização social Xavánte. Os Xavánte possuem um sistema de 
clãs patrilineares (i.e., a criança pertencerá ao clã de seu pai). Três clãs são reconhecidos pelos Xavánte: Poridza'óno, Öwawe e Topdató.

Ainda que o clã seja a unidade fundamental da organização social Xavánte, tendendo a permanecer estável ao longo do tempo, o sistema político opera principalmente através das linhagens. Cada um dos clãs é constituído de várias linhagens: Poridza'ôno (Wamãri e Tebe); Öwawe (Uhö e Dzutsi) e Topdató (Aiuté'mañãri e Wahi) (Figura 1). As relações entre as linhagens tendem a ser conflitantes, uma vez que "... estão em eterna disputa por poder e prestígio..." (Maybury-Lewis, 1967:190).

Os Xavánte consideram incestuoso o casamento entre membros dos clãs Öwawe e Topdató. Os casamentos preferenciais são aqueles entre os membros do clã Poridza'õno e os dois outros. Assim, pode-se afirmar que os Xavánte possuem "um sistema de metades exogâmicas, com dois clãs em uma metade e um na outra" (Maybury-Lewis, 1967:75). Flowers observou, em 1976/1977, que essas regras encontravam-se operantes em Etéñitépa.

Figura 1 - Composição dos clãs (em maiúsculas) e linhagens Xavánte, com as setas indicando o padrão de exogamia prescrita

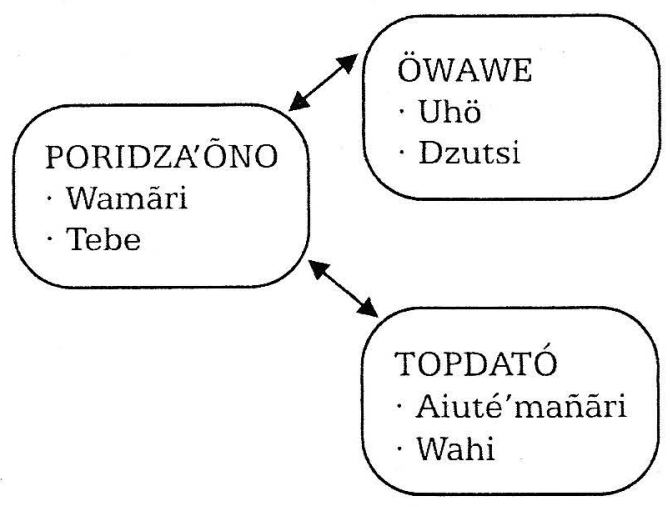

Os Xavánte praticam a poliginia. Entre eles a poliginia é largamente sororal, isto é, se um homem jovem busca uma esposa em um domicílio onde há irmãs, ele pode se casar inicialmente com a mais velha, e a seguir com a irmã ou irmãs mais jovens, à medida que elas atingem a idade apropriada. Alguns homens, após anos de casamento ou após a morte da primeira esposa, podem casar-se com uma mulher muito mais jovem. A poliginia leva a uma situação de constante escassez de mulheres para os homens jovens. Os homens Xavánte não podem casar-se até que sua classe de idade seja iniciada, quando a maior parte deles encontra-se entre os 15 e 18 anos. É ao final da iniciação que cada rapaz irá desposar uma jovem, filiada ao clã apropriado. No entanto, pode se passar um longo tempo antes 
da consumação do casamento, já que os rapazes freqüentemente desposam meninas muito jovens e vários anos são necessários para que elas cheguem à puberdade.

\section{Demografia e mudanças}

Aqui, a análise da demografia dos Xavánte de Etéñitépa será baseada em três períodos: até 1956, de 1957 a 1971 e de 1972 a 1990. Escolheu-se o ano de 1957 como ponto de corte porque a partir desse momento houve importantes mudanças nos padrões de interação entre os Xavánte e os não-índios. MayburyLewis (1967:27-29) demonstra que a segunda metade da década de 50 constituiu um momento decisivo para o grupo. Referiu-se aos Xavánte, nesse período, como "o mais poderoso, o mais numeroso e o menos aculturado" subgrupo Xavánte (1967:27). Quando o antropólogo retornou em 1962, percebeu que grandes mudanças haviam tido lugar, como a diminuição da população graças às epidemias e às disputas políticas. Assim, as evidências etnográficas sugerem que o período que vai de 1957 a 1971 foi sobremodo estressante para os Xavánte. O ano de 1972 foi escolhido como outro ponto de corte, uma vez que foi então que o grupo transferiu a aldeia para sua atual localização (Etéñitépa). As epidemias, que atingiram os Xavánte na década anterior, haviam então retrocedido. Durante as décadas de 70 e 80, ocorreram grandes mudanças nas estratégias de subsistência, o que inclui um estilo de vida mais sedentário e mesmo o cultivo de produtos para o mercado regional. O contato permanente com o mundo exterior tornou-se uma rotina.

\section{Tamanho populacional}

A comparação de dados sobre tamanho da população em Pimentel Barbosa coletados em 1990 com outros obtidos em décadas anteriores mostra tendências bastante claras. A Figura 2 indica os tamanhos populacionais em cinco momentos entre 1958 e 1990. Nas décadas de 1950 e 1960, o tamanho da população manteve-se estável, notando-se um ligeiro decréscimo populacional. A partir de 1969, nota-se um franco crescimento: a população aumentou de aproximadamente 200 para quase 450 pessoas em 1990. Aconteceu, também, alteração na composição etária. Em 1962, Neel et al. (1964:92) observaram que 39\% da população eram compostas de menores de 15 anos. Em 1990, a percentagem havia crescido para $54 \%$, situação que resultou de uma queda da mortalidade e de um aumento da fecundidade, como se verá adiante. 
Figura 2 - Tamanho da população dos Xavánte de Pimentel Barbosa em diferentes períodos

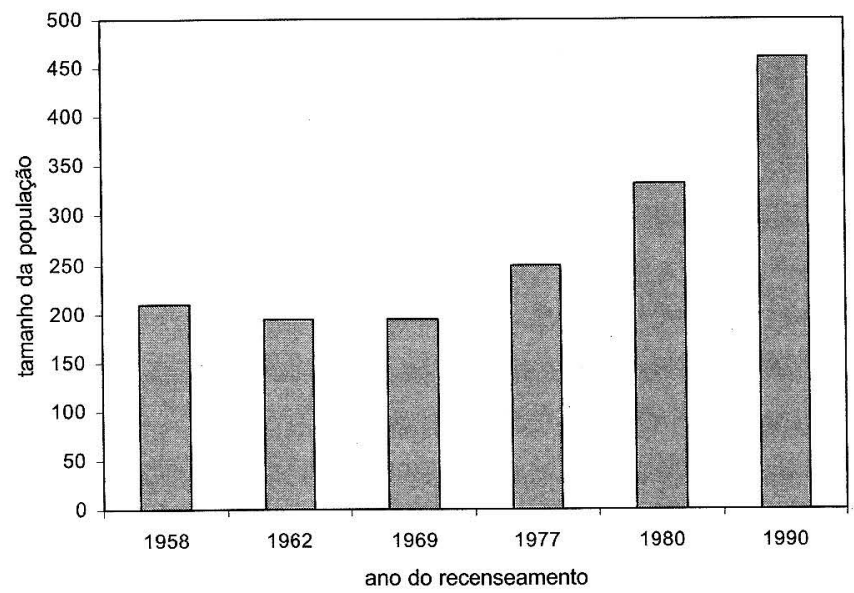

Fonte: Coimbra Jr. et al., 2002.

\section{Tendências da mortalidade em crianças}

Durante as entrevistas com as mulheres Xavánte em 1976/1977 e 1990, perguntou-se não somente quantos filhos elas haviam tido, mas também quais crianças haviam falecido e quando isso ocorrera. Com base nesses dados, caracterizouse a experiência de mortalidade e sobrevivência das crianças menores de dez anos para os três períodos. Os dados apresentados combinam meninos e meninas. Quando foram conduzidas as análises para cada um dos sexos nos três períodos, não se verificou um padrão consistente de maior mortalidade segundo sexo.

Os resultados demonstram claramente que a sobrevivência até os dez anos era muito menor de 1957 a 1971 (43\%) que nos demais períodos. De 1927 a 1956, aproximadamente $73 \%$ dos nascidos chegavam aos dez anos de idade, e de 1972 a 1990 , cerca de $83 \%$ (Tabela 1 ).

As crianças menores de um ano foram as que apresentaram a maior taxa de mortalidade nos três períodos. Quando as taxas de sobrevivência foram as mais baixas (de 1957 a 1971), mais de $20 \%$ das crianças não chegavam a completar um ano de idade (Tabela 1). Nos demais períodos, as taxas observadas foram também maiores entre os menores de um ano.

As epidemias de doenças infecciosas constituíram provavelmente a principal causa do aumento das taxas de mortalidade entre 1957 e 1971. Infelizmente, são escassas as informações acerca da etiologia das mortes que ocorreram nesse período. Além dos relatos de Neel et al. (1964) e de Maybury- 
Lewis (1967), que se referem ao período anterior a 1963, não foi possível obter informações adicionais sobre a situação da comunidade durante a década de 60.

Tabela 1 - Mortalidade e sobrevivência de crianças Xavánte 0-10 anos, sexos combinados, em diferentes períodos

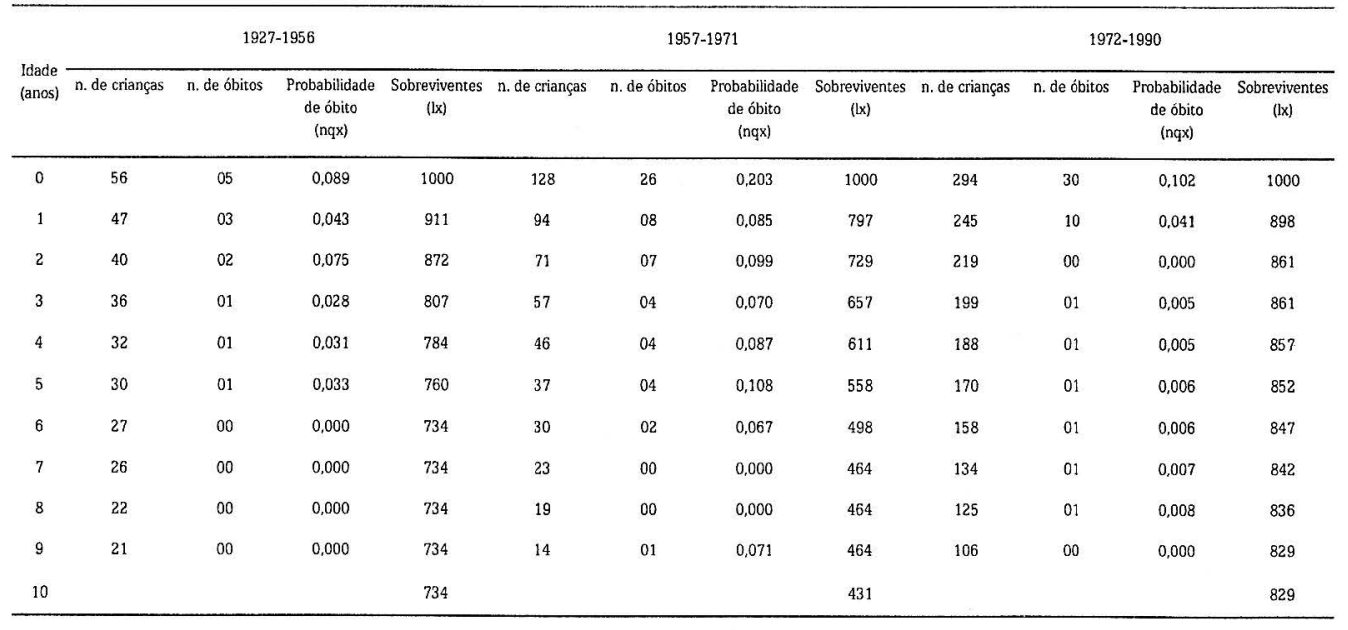

As epidemias de doenças infecciosas freqüentemente precedem ou se seguem imediatamente ao estabelecimento de contato permanente (Ribeiro, 1956; Early G Peters, 1990; Santos G Coimbra Jr., 1998, entre outros). Os Xavánte de Etéñitépa foram o primeiro subgrupo a estabelecer contato pacífico com agentes governamentais, em 1946. Maybury-Lewis (1967:275-276) menciona que, já em 1957, quando caçadores Xavánte seguiram em direção ao rio Araguaia, contraíram gripe em um acampamento de índios Karajá, que mantinham contato freqüente com não-índios. Isto está de acordo com nossos dados demográficos, que sugerem que os Xavánte começaram a experimentar uma elevada mortalidade a partir da segunda década de contato (de 1956 a 1971), e não nos anos que se seguiram imediatamente ao contato. Uma possível razão pela qual a mortalidade veio a aumentar apenas algum tempo após o contato pode ser o fato de que somente em 1953 os Xavánte estabeleceram-se em uma aldeia próxima ao Posto Indígena, construído em um local denominado São Domingos (Maybury-Lewis, 1967:27; Graham, 1995:34). Até então, mesmo que os Xavánte fossem regularmente até o Posto, ainda eram relativamente independentes. A partir do final da década, ficaram muito mais assíduos os contatos com não-índios, fato que pode haver facilitado a introdução de doenças contagiosas. Sob tais condições, é provável que tenham existido colapsos na produção de alimentos, afetando de modo especial as crianças.

No período mais recente (de 1972 a 1990), os níveis de mortalidade entre crianças foram muito mais baixos que aqueles observados entre $1957 \mathrm{e}$ 1971 (Tabela 1). O local em que se encontra atualmente sua aldeia, para onde se 
deslocaram em 1972, é o mesmo que haviam ocupado na década de 40 e no início da década seguinte. Os Xavánte afirmam que retornaram para Etéñitépa porque o consideram um lugar 'saudável' e onde a terra é boa para a agricultura, o que implica que pode haver melhorado o estado nutricional do grupo. Nas décadas de 70 e 80 , embora não regularmente, os Xavánte também recebiam as vacinas fornecidas pelo Ministério da Saúde (BCG, antipólio, anti-sarampo e tríplice), o que pode haver exercido algum efeito sobre a mortalidade.

\section{Tendências da fecundidade}

A Tabela 2 apresenta as taxas específicas de fecundidade (TEF) e as taxas de fecundidade total (TFT) para as mulheres Xavánte, segundo os três períodos.

Para 1972-1990, quando é maior a amostra, observa-se que a fecundidade eleva-se cedo, aos 10-14 anos, atingindo o maior valor aos 20-24 anos, com declínio posterior. Por mais que as mulheres Xavánte comecem a ter filhos já no início da segunda década de vida (correntemente em torno dos 13-14 anos), a TEF da faixa etária de 10-14 anos é muito baixa. As gestações também parecem cessar relativamente cedo, já que a fecundidade das mulheres com idade entre 40-44 anos é próxima de zero.

Tabela 2 - Taxas específicas de fecundidade (TEF) e taxas de fecundidade total (TFT) para mulheres Xavánte, entre 10-44 anos, em diferentes períodos

\begin{tabular}{cccc}
\hline Idade (anos) & $1942-1956$ & $1957-1971$ & $1972-1990$ \\
\hline $10-14$ & 0,056 & 0,068 & 0,050 \\
$15-19$ & 0,339 & 0,359 & 0,356 \\
$20-24$ & 0,263 & 0,240 & 0,412 \\
$25-29$ & 0,300 & 0,232 & 0,323 \\
$30-34$ & 0,438 & 0,143 & 0,246 \\
$35-39$ & 0,100 & 0,135 & 0,183 \\
$40-44$ & 0,125 & 0,000 & 0,000 \\
\hline TFT & 8,01 & 5,88 & 7,86 \\
\hline
\end{tabular}

Os ,resultados evidenciam que a fecundidade Xavánte alcançou seu nível mais baixo entre 1957 e 1971 (TFT=5,88). Logo, o final da década de 50 e a década seguinte foram não apenas um período de elevada mortalidade, mas também de queda da fecundidade. Um período marcado pela ruptura social, o que possivelmente resultou em um aumento da instabilidade dos casamentos e também em viuvez precoce para algumas mulheres. Pelas histórias reprodutivas, observa-se 
que onze mulheres, embora com idades próximas de vinte anos, separaram-se de seus esposos ou tornaram-se viúvas na década de 60, havendo um período sem nascimentos até que se casassem novamente. Apesar de os Xavánte serem poligínicos, algumas mulheres podem permanecer sozinhas após a viuvez ou a separação. Ainda que nesta situação possam ter mais um ou dois filhos, é de se esperar que sua fecundidade seja mais baixa que a de mulheres que se encontram em uniões estáveis durante seu período reprodutivo. Em 1976-1977, quando Flowers permaneceu em Etéñitépa, todas as mulheres na faixa dos vinte anos estavam casadas.

A fecundidade das mulheres Xavánte entre 1957 e 1972 (TFT=5,88) foi cerca de $25 \%$ mais baixa, quando comparada aos dois outros períodos. Algumas mulheres afirmaram que, vendo tantas de suas crianças morrerem, incluindo algumas que já não eram mais tão pequenas, "perderam a vontade de ter filhos". Entre os Bororo, outro grupo do Brasil Central, uma mortalidade infantil muito elevada e a redução dos nascimentos redundaram em um declínio acentuado da população; as mulheres constantemente declaravam seu desejo de não ter mais filhos, justificandose com a frase "Eu não quero ver a criança morrer!" (Crocker, 1985:47).

As mulheres Xavánte, contudo, apesar da gravidade da crise que o grupo enfrentava, ainda davam à luz em média a seis crianças. Uma razão para isto pode ter sido uma crescente interação mortalidade-fecundidade durante o período. Em uma revisão sobre a fecundidade nas chamadas 'populações antropológicas', Wood (1990:233-234) afirma que uma das questões mais significativas a serem ainda abordadas na literatura diz respeito às interações entre fecundidade e mortalidade. Segundo esse autor, existem crescentes evidências de que um importante fator de regulação dos níveis de fecundidade em sociedades pré-industriais não é a reprodução em si, mas a mortalidade. O que nos interessa do argumento de Wood é a interação entre a mortalidade infantil e a fecundidade, a que ele se refere como "compensação reprodutiva". Afirma: "quando um bebê morre, a lactação é interrompida e a mãe volta a ovular mais cedo do que ocorreria normalmente" (Wood, 1990:233). Assim, paradoxalmente, em uma situação de elevada mortalidade infantil, a TFT de um determinado grupo de mulheres pode até mesmo aumentar em função de uma redução dos intervalos interpartais. Esta, por sua vez, está associada à interrupção antecipada da lactação e ao conseqüente retorno da ovulação.

Os dados coletados não possibilitam afirmações conclusivas com relação à influência da mortalidade infantil na fecundidade Xavánte; porém, o período entre 1957 e 1971 foi por certo uma época em que este tipo de interação pode haver ocorrido mais corriqueiramente. As probabilidades de óbito nos dois primeiros anos de vida, de 1957 a 1971 (0,203), foram pelo menos duas vezes maior que nos dois outros períodos $(0,089$ e 0,102$)$ (Tabela 1$)$. Isto é, proporcionalmente, as mães Xavánte estavam então perdendo mais crianças que ainda eram amamentadas. 
Parece razoável argumentar que, com a morte de um crescente número de bebês, e com a diminuição do período em que permaneciam amamentando, as mulheres Xavánte apresentavam, naquela época, uma probabilidade maior de engravidar. Durante aqueles anos, as mulheres Xavánte podem ter tido mais filhos, pois com a morte precoce de seus bebês ocorria uma redução dos períodos de infertilidade em virtude da lactação.

Entre 1974 e 1976, o responsável pelo posto indígena que vivia em Etéñitépa registrou as datas dos nascimentos e das mortes. Flowers fez o mesmo durante sua estada na aldeia em 1976-1977. Esses dados, ainda que de fontes diversas, mostram uma associação entre a ocorrência de óbitos infantis e a duração dos intervalos entre os nascimentos. Durante 33 meses de cuidadosos registros, 42 das 65 mulheres com idades entre 15 e 44 anos deram à luz pelo menos uma vez (contando-se apenas os nascidos vivos). Durante este período, catorze mulheres tiveram dois filhos, e apenas uma mulher pariu três. O intervalo interpartal médio foi igual a 20,9 meses entre as mulheres cujos bebês viveram pelo menos até a idade de um ano, e de 16,6 meses entre aquelas cujos bebês haviam morrido antes disso.

Portanto, o declínio da fecundidade nas mulheres não revela na mesma magnitude, se comparada à mortalidade, a dimensão da crise enfrentada pelos Xavánte de Etéñitépa no período pós-contato, talvez em função dos efeitos da compensação reprodutiva.

\section{Epidemias, demografia e ordem social}

Nem todas as mortes ocorridas durante as epidemias pós-contato estão diretamente ligadas a doenças. Quando uma enfermidade estranha e debilitante atinge uma comunidade, a população pode ficar assustada e desorientada, e os laços que normalmente unem indivíduos aparentados podem entrar em colapso. As mulheres que adoecem podem não conseguir alimentar e cuidar de seus filhos (Neel, 1982). O estado nutricional do grupo pode sofrer um impacto adicional, caso a doença impeça os homens de saírem para caçar ou obste as mulheres da coleta de alimentos silvestres e da ida às roças (McGrath, 1991).

À proporção que o aumento da mortalidade ocasiona acusações de feitiçaria e mortes por vingança, uma importante causa indireta de morte entre adultos pode ser a punição de 'bodes expiatórios' (Ross, 1984; Early G Peters, 1990:80; Ferguson, 1990). Em algumas sociedades amazônicas, 'causas naturais' (como doenças) nunca são aceitas como motivos para as mortes (Wagley, 1977:171-172; Seeger, 1981:219-220; Crocker, 1985:36-37). Outras distinguem de diversas maneiras as mortes ocorridas graças às 'causas naturais' daquelas cuja origem 
encontra-se no mundo espiritual ou em feitiços enviados por indivíduos 'maléficos' (ver Buchillet, 1992:216; Crocker G Crocker, 1994:170; Langdon, 1992b:50).

Fundamentando-se em suas observações etnográficas sobre os Xavánte nas décadas de 50 e 60, Maybury-Lewis registrou:

Eles possuem alguma compreensão do contágio e estão conscientes, por exemplo, de que quando entram em contato com um brasileiro que tem tosse, estão sujeitos a contraí-la. E, caso adoeçam, não acreditarão que foram enfeitiçados, a menos que tenham uma boa razão para isso. (1967:274)

Mas o intenso faccionalismo que sempre ameaça a sociedade Xavánte foi exacerbado pelo número não usual de mortes, freqüentemente de homens proeminentes, como veremos.

Quase todas as sociedades amazônicas possuem especialistas espirituais, indivíduos que afirmam poder comunicar-se com os espíritos e influenciar o destino humano curando doenças ou, ao contrário, fazendo o mal (Langdon, 1992a:3-5). Estes especialistas, quase sempre referidos na literatura como xamãs, normalmente não são líderes de facções ou do grupo; em lugar disso, seu poder vem do modo como podem usar seu conhecimento espiritual para o bem ou para o mal. Um mesmo indivíduo que cura como um xamã pode ser suspeito de feitiçaria quando aumenta o número de mortes inexplicadas, chegando eventualmente a ser executado (Wagley, 1977:186-189; Seeger, 1981:86-88, 174; Crocker G Crocker, 1994:112-113). A concentração das suspeitas sobre um indivíduo que acreditam possuir poderes xamãnicos e sua eventual eliminação da sociedade pode, assim, limitar a agitação social que caracteriza tais momentos.

Os Xavánte não vêem a feitiçaria como um atributo de certos indivíduos que possuem tal poder.

Eles acreditam que um Xavánte só pode infligir doença ou morte a outro através do poder de certos rituais que envolvem a manipulação de substâncias ou implementos mágicos. Estas substâncias são pós, que podem ser usados tanto ofensiva como defensivamente. (Maybury-Lewis, 1967:276)

Somente os homens são suspeitos de praticá-la. Quando um homem proeminente adoece ou morre, as suspeitas recaem sobre aqueles que possivelmente teriam mais a ganhar com sua morte. Um evento desta natureza pode desencadear uma disputa em que os homens da facção mais fraca são mortos ou expulsos da aldeia. Como Maybury-Lewis (1967:188-189) assinala, um caso de feitiçaria é uma questão política, já que "todos as questões Xavánte constituem essencialmente questões entre grupos, e não disputas entre indivíduos". Em lugar de se concentrar sobre um único indivíduo, a culpa recai sobre toda a facção ou linhagem. 
Para Maybury-Lewis, nos anos que se seguiram ao contato, ao final da década de 40, o líder Apowe e sua família mantiveram sua influência, por intermédio da distribuição de 'presentes' dados pelos agentes do SPI e também pelo antropólogo (Maybury-Lewis, 1967:28, 171). A introdução de bens manufaturados afetou a comunidade, acirrando a disputa entre as linhagens, a ponto de membros da linhagem Wamãri mobilizarem-se para eliminar outras facções, de modo a assegurarem o controle sobre a distribuição de bens de consumo.

Uma epidemia de gripe que teve lugar em meados de 1960 (MayburyLewis, 1967:176) aparentemente desencadeou uma série de acusações de feitiçaria que, unida à própria doença, reduziu ainda mais a população. Os detalhes do que, de verdade, aconteceu são difíceis de esclarecer.

Alguns membros da linhagem Wamări morreram em uma epidemia de gripe. A facção responsabilizou o clã Topdató e assassinou alguns de seus integrantes... Eu nunca pude determinar quantos Topdató foram mortos, já que os inimigos dos Wamãri veementemente atribuíam todas as mortes ocorridas desde a minha última visita à ferocidade da facção dominante. Os Wamãri asseguraram-me, por outro lado, que nenhum Topdató fora morto por eles. Insistiam em que os membros deste clã haviam sofrido ainda mais intensamente os efeitos da epidemia do que os Wamãri. Parece certo, entretanto, que alguns Topdató foram de fato assassinados, embora alguns possam haver morrido de gripe. (Maybury-Lewis, 1967:176)

No início da década de 60 já começava a ficar nítido que as disputas em São Domingos (o local onde os Xavánte viveram até 1962, antes de se mudarem para Etéñitépa) estavam produzindo efeitos visíveis sobre a composição social do grupo:

À época de minha segunda visita [em 1962]... Os Wamãri ainda estavam firmemente estabelecidos como a linhagem dominante, pois havia poucos que pudessem se opor a eles. As únicas linhagens ainda representadas na aldeia eram, respectivamente, os Uhö e os Dzutsi, ambas consideravelmente incompletas... São Domingos era uma das mais homogêneas aldeias que eu havia visitado, em termos de facções. (1967:177)

• Crise demográfica e organização social

Na parte final deste texto, serão exploradas algumas relações entre disputas políticas, violência e mortes por causa das epidemias, e serão investigados seus impactos sobre aspectos específicos da demografia e da dinâmica social Xavánte. Ver-se-á que, a longo prazo, a quase completa eliminação de certos clãs e linhagens levou a desequilíbrios sociais que vieram a afetar os arranjos de casamentos. 
Em 1976/1977, Flowers coletou dados genealógicos detalhados, incluindo informações sobre filiação a clãs e linhagens dos residentes de Etéñitépa. A comparação dos dados da década de 70 com os censos e genealogias registrados por Maybury-Lewis em 1958 e 1962 fornece fortes evidências das relações entre crise demográfica e disputas políticas, e dos impactos a longo prazo que daí resultam sobre a organização social Xavánte.

Conduziu-se uma análise comparativa quanto ao número de homens e mulheres adultos Xavánte dos três clãs e das várias linhagens registradas por Maybury-Lewis, no final da década de 50 e início da de 60, com aqueles presentes em Etéñitépa em 1976-1977. Buscou-se investigar o que havia acontecido com aqueles que não se encontravam mais na aldeia (o número de indivíduos que havia falecido, mudado de aldeia etc.). O achado mais marcante é que já não havia homens integrantes das linhagens Poridza'õno Tebe, Topdató Aiutémañãri e Topdató Wahi em Etéñitépa na década de 1970. Isto é, o grupo estava ainda mais homogêneo, no que se refere às facções, do que nas décadas anteriores.

Com o objetivo de revelar este padrão de modo mais claro, foram reunidos os dados em dois grupos: homens e mulheres da linhagem dominante (Poridza'óno Wamãri) e homens e mulheres das demais linhagens (Tabela 3). De um total de 23 homens e 23 mulheres Wamãri registrados nas genealogias e censos de MayburyLewis, mais da metade dos homens (17 indivíduos, ou 74\%) e das mulheres (12 indivíduos, ou 52\%) ainda viviam em Etéñitépa em 1976/1977. Para as demais linhagens, a redução foi muito maior, particularmente no caso dos homens. Somente $28 \%$ dos homens e $42 \%$ das mulheres não Wamãri registrados por Maybury-Lewis ainda viviam em Etéñitépa na década de 70. Mais marcante é o fato de que a maior causa de redução populacional entre os homens não Wamãri foi a morte, responsável por 56\% da diminuição do número de indivíduos. Apenas 18\% dos homens Wamãri vieram a morrer entre os períodos de 1958-1962 e 1976/1977. Como é improvável que diferentes linhagens vivendo na mesma aldeia experimentem distintas taxas de mortalidade em virtude das epidemias, é mais cabível que a redução nas linhagens não dominantes deveu-se a disputas políticas.

Os Wamãri foram, inquestionavelmente, a força política dominante em Etéñitépa na década de 70. Com base nos dados genealógicos e censitários, Flowers verificou que, em 1977, dos 28 homens com idade acima de 30 anos, 19 eram Wamãri. Curiosamente, apesar de esta linhagem haver alcançado um controle político quase total, seus membros foram forçados a enfrentar alguns problemas de ordem social, ocasionados pelo desequilíbrio entre os clãs. Segundo as regras matrimoniais Xavánte, os Wamãri, filiados ao clã Poridza'õno, supostamente deveriam tomar como esposas mulheres pertencentes aos outros dois clãs. Todavia, tantos homens Öwawe e Topdató morreram na década de 60, que poucas filhas que os Wamãri pudessem desposar foram geradas. 
Tabela 3 - Destino dos adultos Xavánte presentes em São Domingos em 1958/1962 no ano de 1977, de acordo com sexo e linhagem

\begin{tabular}{|c|c|c|c|c|c|c|}
\hline \multirow{2}{*}{ Linhagens } & \multicolumn{2}{|c|}{ Homens } & \multicolumn{2}{|c|}{ Mulheres } & \multicolumn{2}{|c|}{ Ambos os Sexos } \\
\hline & $\begin{array}{l}\text { Poridza'óno } \\
\text { Wamâri }\end{array}$ & $\begin{array}{c}\text { Demais } \\
\text { linhagens }\end{array}$ & $\begin{array}{l}\text { Poridza'óno } \\
\text { Wamãri }\end{array}$ & $\begin{array}{c}\text { Demais } \\
\text { linhagens }\end{array}$ & $\begin{array}{l}\text { Poridza'óno } \\
\text { Wamãri }\end{array}$ & $\begin{array}{c}\text { Demais } \\
\text { linhagens }\end{array}$ \\
\hline $\begin{array}{l}\text { Vivendo em } \\
\text { São Domingos } \\
\text { em 1958/1962 }\end{array}$ & $\begin{array}{c}23 \\
(100 \%)\end{array}$ & $\begin{array}{c}25 \\
(100 \%)\end{array}$ & $\begin{array}{c}23 \\
(100 \%)\end{array}$ & $\begin{array}{c}43 \\
(100 \%)\end{array}$ & $\begin{array}{c}46 \\
(100 \%)\end{array}$ & $\begin{array}{c}68 \\
(100 \%)\end{array}$ \\
\hline $\begin{array}{l}\text { Faleceram entre } \\
1958 / 1962 \text { e } 1977\end{array}$ & $\begin{array}{c}04 \\
(17 \%)\end{array}$ & $\begin{array}{c}14 \\
(56 \%)\end{array}$ & $\begin{array}{c}07 \\
(30 \%)\end{array}$ & $\begin{array}{c}17 \\
(40 \%)\end{array}$ & $\begin{array}{c}11 \\
(24 \%)\end{array}$ & $\begin{array}{c}31 \\
(46 \%)\end{array}$ \\
\hline $\begin{array}{l}\text { Mudaram-se entre } \\
1958 / 1962 \text { e } 1977\end{array}$ & $\begin{array}{c}02 \\
(9 \%)\end{array}$ & $\begin{array}{c}02 \\
(8 \%)\end{array}$ & $\begin{array}{c}01 \\
(4 \%)\end{array}$ & $\begin{array}{c}02 \\
(5 \%)\end{array}$ & $\begin{array}{c}03 \\
(7 \%)\end{array}$ & $\begin{array}{c}04 \\
(6 \%)\end{array}$ \\
\hline $\begin{array}{c}\text { Destino } \\
\text { desconhecido entre } \\
\text { 1958/1962 e } 1977\end{array}$ & $\tilde{N}$ & $\begin{array}{c}02 \\
(8 \%)\end{array}$ & $\begin{array}{c}03 \\
(13 \%)\end{array}$ & $\begin{array}{c}06 \\
(14 \%)\end{array}$ & $\begin{array}{c}03 \\
(7 \%)\end{array}$ & $\begin{array}{c}08 \\
(12 \%)\end{array}$ \\
\hline $\begin{array}{l}\text { Vivendo em } \\
\text { Etéñitépa em } 1977\end{array}$ & $\begin{array}{c}17 \\
(74 \%)\end{array}$ & $\begin{array}{c}07 \\
(28 \%)\end{array}$ & $\begin{array}{c}12 \\
(52 \%)\end{array}$ & $\begin{array}{c}18 \\
(42 \%)\end{array}$ & $\begin{array}{c}29 \\
(63 \%)\end{array}$ & $\begin{array}{c}25 \\
(37 \%)\end{array}$ \\
\hline
\end{tabular}

Nota: Informações sobre 1958/1962 derivadas de genealogias e recenseamentos conduzidos por Maybury-Lewis (1967:317-342).

Em 1976/1977, havia 11 jovens Wamãri do sexo masculino, com idade entre 15 e 25 anos, que já haviam sido iniciados. Tinham, portanto, o direito de se casar, buscando suas esposas, segundo as regras Xavánte de exogamia entre os clãs, entre as mulheres Öwawe e Topdató. Flowers observou que apenas três desses jovens conseguiram encontrar esposas. Embora houvesse sete moças Öwawe com idades entre 10 e 20 anos, três delas se casaram com homens mais velhos, e uma quarta foi destinada a um jovem que se encontrava fora da aldeia. Logo, havia apenas três moças disponíveis para o casamento, enquanto eram 11 os jovens Wamâri. Enquanto isso, a situação dos jovens Öwawe era muito diferente. Dos nove jovens deste clã entre os 15 e os 25 anos de idade, sete já estavam casados, três deles com mais de uma esposa. Havia uma tal 'abundância' de jovens mulheres Poridza'õno Wamãri para os rapazes Öwawe desposarem, que quatro jovens homens pertencentes a este clã mudaram-se de outras aldeias para Etéñitépa e lá se casaram.

$\mathrm{Na}$ década de 70, Flowers previu uma tendência de aumento do clã Öwawe, já que os homens que o integravam estavam tendo mais acesso às mulheres. Ela afirmou: "Os jovens Öwawe casaram-se com mulheres no auge de sua fecundidade e estavam claramente tendo mais filhos que os Wamãri de sua idade" (Flowers, 1983:179). A comparação dos dados dos censos de 1976/1977 e 1990 demonstra que, de fato, durante todo este período, reduziu-se o tamanho relativo dos Poridza'óno Wamãri (de 55\% para 48\% da população). O aumento da presença de indivíduos não Wamãri se deve, sobretudo, ao grande número de menores de 
15 anos, nascidos de 1975 a 1990, e filhos de homens Öwawe. Da década de 1970 até a de 1990, a proporção de indivíduos não Wamãri menores de quinze anos cresceu de $44 \%$ para $58 \%$.

A análise anterior demonstra que, devido a um mecanismo construído dentro da estrutura de parentesco, ou seja, à medida que os Xavánte evitem os casamentos intraclânicos, é impossível para uma linhagem crescer indefinidamente sem que tenha de lidar com algumas conseqüências adversas, originadas pela sua própria dominação política e hegemonia demográfica.

\section{Considerações finais}

Os Xavánte de Pimentel Barbosa passaram por uma severa crise demográfica nas décadas que se seguiram ao contato com a sociedade nacional brasileira nos idos de 1940. A crise foi resultado de níveis mais elevados de mortalidade, em virtude tanto das epidemias de doenças infecciosas quanto da violência, além de uma queda da fecundidade. Combinados, tais fatores ameaçaram, durante a década de 60, a sobrevivência biológica do grupo. A partir da década de 70 , decresceu a mortalidade e aumentou a fecundidade, e a população iniciou um período de rápido crescimento.

A crise demográfica Xavánte pode não diferir muito daquelas que tiveram lugar em centenas de outros povos indígenas do Novo Mundo, desde o século XV, e que resultaram num colapso demográfico de dimensões continentais (Crosby, 1972; Ribeiro, 1977; Dobyns, 1983; Hemming, 1987; Denevan, 1992; Cook, 1998; Santos G Coimbra Jr., 2003). A literatura etnológica amazônica é repleta de relatos que descrevem a ocorrência de crises demográficas pós-contato. No entanto, essas crises só foram detalhadamente documentadas, por intermédio de dados demográficos, em um pequeno número de sociedades indígenas (Black et al., 1978; Werner, 1983; Early G Peters, 1990, 2000; Adams G Price, 1994; Flowers, 1994; Pagliaro, 2002). Para muitos deles, amazônicos ou não, a crise foi de tal modo severa, que o declínio populacional tornou-se irreversível, redundando em sua extinção biológica.

No caso Xavánte, a crise demográfica foi influenciada não somente por fatores externos, mas também por aspectos ligados à organização social. Durante $o$ período de epidemias, acusações de feitiçaria tornaram-se mais freqüentes, exacerbando disputas intragrupais. Evidências etnográficas, assim como dados demográficos, mostram que a violência atingiu, sobretudo, os homens das facções politicamente mais fracas. O exemplo Xavánte demonstra que, embora as crises demográficas tenham sido uma experiência quase universal na história dos povos indígenas, os efeitos podem variar de acordo com características socioculturais específicas. Adicionalmente, o caso dos Xavánte indica que o impacto das epidemias 
envolve mais que a redução da população, influenciando dinâmicas sociais, como as práticas matrimoniais, mesmo décadas após a crise propriamente dita.

Apesar de todas as adversidades, os povos indígenas estão em franco crescimento no Brasil, com taxas que superam as médias nacionais. Num dado momento, nas décadas de 50 e 60, antevia-se que o futuro dos povos indígenas seria ou o desaparecimento físico e cultural ou a assimilação na sociedade envolvente, vaticínios que felizmente não se confirmaram. Nessa trajetória, as crises do contato fazem parte do passado de praticamente todos os grupos que sobreviveram (sequer sabemos quantos se extinguiram). Registrá-las e resgatálas, etnográfica e também demograficamente, contribui para uma melhor compreensão da história recente desses povos, especialmente no bojo do expansionismo ocidental. São exemplos de sofridas e íntimas, mas também, com certeza, fascinantes vinculações entre história, cultura, sociedade e demografia, como bem evidencia o processo vivido pelos Xavánte.

Agradecimentos

A pesquisa foi financiada pela Wenner-Gren Foundation, pela MacArthur Foundation e pela Fundação Oswaldo Cruz. Agradecemos também ao Conselho Nacional para o Desenvolvimento Científico e Tecnológico (CNPq) e à Comissão Fullbright. Os autores são especialmente gratos aos Xavánte, e às mulheres em particular, por sua paciência em responder a todas as suas perguntas.

Nota

1 Uma versão mais extensa e detalhada deste trabalho encontra-se como capítulo no livro The Xavánte in Transition: health, ecology and bioanthropology in Central Brazil (Coimbra Jr. et al., 2002).

\section{Referências Bibliográficas}

ADAMS, K. G PRICE, D. (Orgs.) The demography of small-scale societies: case studies from Iowland South America. South American Indian Studies, 4, 1994.

BLACK, F. L. et al. Birth and survival patterns in numerically unstable proto agricultural societies in the Brazilian Amazonia. Medical Anthropology, 2:95-127, 1978. 
BUCHILLET, D. Nobody is there to hear: Desana therapeutic lamentations. In: LANGDON, E. J. M. G BAER, G. (Orgs.) Portals of Power: shamanism in South America. Albuquerque: University of New Mexico Press, 1992. p.211-230.

CHAGNON, N. A. Yanomamo: the fierce people. 3.ed. New York: Holt, Rinehart and Winston, 1983.

COIMBRA Jr., C. E. A. From Shifting Cultivation to Coffee Farming: the impact of change on the health and ecology of the suruí indians in the Brazilian Amazon, 1989. Ph.D. Dissertation, Bloomington: Indiana University.

COIMBRA Jr., C. E. A. et al. The Xavánte in Transition: health, ecology and bioanthropology in Central Brazil. Ann Arbor: University of Michigan Press, 2002.

COOK, N. D. Born to Die: disease and new world conquest, 1492-1650. Cambridge; Cambridge University Press, 1998.

CROCKER, J. C. Vital Souls: Bororo cosmology, natural symbolism, and shamanism. Tucson: The University of Arizona Press, 1985.

CROCKER, W. G CROCKER, J. The Canela: bonding through kinship, ritual, and sex. Fort Worth: Harcourt Brace, 1994.

CROSBY, A. W. The Columbian Exchange: biological and cultural consequences of 1492. Westport: Greenwood Press, 1972.

DENEVAN, W. M. (Org.) The Native Populations of the Americas in 1492. 2.ed. Madison: University of Wisconsin Press, 1992.

DOBYNS, H. F. Their Numbers Become Thinned: native American Population dynamics in Eastern North America. Knowville: University of Tennessee Press, 1983.

EARLY, J. D. G PETERS, J. F. The Population Dynamics of the Mucajai Yanomama. San Diego: Academic Press, 1990.

EARLY, J. D. G PETERS, J. F. The Xilixana Yanomami of the Amazon. Gainesville: University Press of Florida, 2000.

EARLY, J. D. G HEADLAND, T. N. Population Dynamics of a Philippine Rain Forest People. Gainesville: University Press of Florida, 1998.

FERGUSON, R. B. Blood of the Leviathan: Western contact and warfare in Amazonia. American Ethnologist, 17:237-257, 1990.

FLOWERS, N. M. Forager-Farmers: the Xavánte indians of Central Brazil, 1983. Ph.D. Dissertation, New York: City University of New York.

GARFIELD, S. W. Indigenous Struggle at the Heart of Brazil: state policy, frontier expansion, . and the Xavante indians, 1937-1988. Durham: Duke University Press, 2001.

GOMES, M. P. Os Índios e o Brasil: ensaio sobre um holocausto e sobre uma nova possibilidade de convivência. Petrópolis: Vozes, 1988.

GRAHAM, L. R. Performing Dreams: discourses of immortality among the Xavánte of Central Brazil. Austin: University of Texas Press, 1995. 
HEMMING, J. Amazon Frontier: the defeat of the Brazilian indians. Cambridge: Cambridge University Press, 1987.

HILL, K. G HURTADO, A. M. Ache Life History: the ecology and demography of a foraging people. Hawthorne: Aldine de Gruyter, 1996.

HOWELL, N. Demography of the Dobe !Kung. New York: Academic Press, 1979.

LANGDON, E. J. M. Shamanism and anthropology. In: LANGDON, E. J. M. G BAER, G. (Orgs.) Portals of Power: shamanism in South America. Albuquerque: University of New Mexico Press, 1992a. p.1-21.

LANGDON, E. J. M. Shamanic power in Siona religion and medicine. In: LANGDON, E. J. M. G BAER, G. (Orgs.) Portals of Power: shamanism in South America. Albuquerque: University of New Mexico Press, 1992b. p.41-61.

LOPES DA SILVA, A. Dois séculos e meio de história Xavante. In: Cunha, M. C. (Org.) História dos Índios no Brasil. São Paulo: Companhia das Letras, 1992. p.357-378.

MAYBURY-LEWIS, D. Akwe-Shavante Society. Oxford: Clarendon Press, 1967.

MCGRATH, J. W. Biological impact of social disruption resulting from epidemic disease. American Journal of Physical Anthropology, 84:407-419, 1991.

NEEL, J. V. Infectious disease among Amerindians. Medical Anthropology, 6:47-55, 1982.

NEEL, J. V. et al. Studies on the Xavante Indians of the Brazilian Mato Grosso. American Journal of Human Genetics, 16:52-140, 1964.

PAGLIARO, H. A Revolução Demográfica dos Povos Indígenas: a experiência dos Kaiabi do Parque Indígena do Xingu, Mato Grosso (1970-1999), 2002. Tese de Doutorado, São Paulo: Faculdade de Saúde Pública, Universidade de São Paulo.

RIBEIRO, D. Convívio e contaminação: efeitos dissociativos da depopulação provocada por epidemias em grupos indígenas. Sociologia, 18:3-50, 1956.

RIBEIRO, D. Os Índios e a Civilização: a integração das populações indígenas no Brasil moderno. 2.ed. Petrópolis: Vozes, 1977.

ROSS, J. B. Effects of contact on revenge hostilities among the Achuara Jivaro. In: FERGUSON, R. B. (Org.) Warfare, Culture and Environment. Orlando: Academic Press, 1984. p.83-109.

SANTOS, R. V. et al. Tapirs, tractors and tapes: The changing ecology and economy of the Xavánte Indians from Central Brazil. Human Ecology, 25:545-566, 1997.

SANTOS, R. V. G COIMBRA Jr., C. E. A. On the (un)natural history of the Tupí-Mondé Indians: Bioanthropology and change in the Brazilian Amazonia. In: GOODMAN, A. H. G LEATHERMAN, T. (Orgs.) Building a New Biocultural Synthesis: politicaleconomic perspectives on human biology. Ann Arbor: University of Michigan Press, 1998. p.269-294.

SANTOS, R. V. G COIMBRA Jr., C. E. A. Cenários e tendências da saúde e da epidemiologia dos povos indígenas no Brasil. In: COIMBRA Jr., C. E. A.; SANTOS, R. V. G ESCOBAR, A. L. (Orgs.) Epidemiologia e Saúde dos Povos Indígenas no Brasil. Rio de Janeiro: Ed. Fiocruz/Associação Brasileira de Saúde Coletiva - Abrasco, 2003. p.13-47. 
SEEGER, A. Nature and Society in Central Brazil: the Suya indians of Mato Grosso. Cambridge: Harvard University Press, 1981.

WAGLEY, C. Welcome of Tears: the Tapirapé indians of Central Brazil. New York: Oxford University Press, 1977.

WERNER, D. W. Fertility and pacification among the Mekranoti of Central Brazil. Human Ecology, 11:227-245, 1983.

WOOD, J. W. Fertility in anthropological populations. Annual Review of Anthropology, 19:211-242, 1990. 